\title{
Fenomenologiaaplicada à performance musical: um recorte na peça Bajulans de Manoel Dias de Oliveira
}

\author{
Sérgio de Figueiredo Rocha (UFSJ) \\ sergiorocha@ufsj.edu.br
}

\begin{abstract}
Resumo: 0 presente trabalho propõe a análise musical fenomenológica como ferramenta facilitadora no processo de performance. A peça em questão é Bajulans, do Moteto de Passos, do compositor colonial mineiro Manoel Dias de Oliveira (1734/5-1813). Entender como se estrutura uma peça do ponto de vista harmônico e aplicar sobre ela uma análise musical fenomenológica é um dos procedimentos que podem contribuir para uma melhor elaboração interpretativa da mesma. A análise fenomenológica da música ainda é uma abordagem pouco usual na prática interpretativa. Contudo, parâmetros eminentemente subjetivos, como a vivência do intérprete em performance, têm se revelado bastante significativos para a pesquisa em música.
\end{abstract}

Palavras-chave:música colonial brasileira, fenomenologia da música, performance musical.

Phenomenology applied to the musical performance: an approach to the piece Bajulans by Manoel Dias de Oliveira

Abstract: The purpose of this article is to present a phenomenological analysis of Bajulans from Moteto de Passos, a work by colonial Brazilian composer Manoel Dias de Oliveira (1734/5-1813). Understanding how the piece is structured from the harmonic and phenomenological point of view may contribute to improve its performance. The phenomenological analysis is not a common approach in the interpretation of music yet. However, parameters eminently subjective, as the interpreter's experience in performance, have been shown to be quite significant for music research.

Keywords: Brazilian colonial music, phenomenology of music, musical performance.

\section{1- Introdução}

0 presente trabalho propõe um melhor entendimento do processo de construção interpretativa. Para tanto, é necessária uma abordagem que se aproxime essencialmente da experiência musical, sem, contudo, se distanciar do contexto mais amplo ao qual está inserida a estruturação da peça. Nesse sentido, a fenomenologia é o referencial apropriado. A fenomenologia é um campo da filosofia que busca descrever os fenômenos a partir da consciência subjetiva dos objetos. Da mesma forma, a fenomenologia da música trata de abordar essas questões de maneira mais particularizada. Bajulans, peça do Moteto de Passos de Manoel Dias de Oliveira - compositor do período colonial brasileiro - traz um interesse particular, pois é composta originalmente para canto, e, portanto, oferece mais uma sofisticação, que é o texto. Ocorre que na execução de transcrições, sobretudo para instrumentos de sopro (onde a palavra não é articulada), não se pode perder o significado desse texto. Essa questão é fundamental no processo interpretativo. Apreender o significado desse texto, traduzi-lo em parâmetros objetivos na execução musical e correlacioná-los com aspectos da harmonia é um exercício de construção interpretativa. Partindo desses referenciais, o presente trabalho busca apontar a análise musical fenomenológica como recurso facilitador da elaboração interpretativa.

\section{2- Fundamentação Teórica}

Em fins do século XIX e princípios do século XX, havia uma crise entre o Positivismo e o Irracionalismo. Edmund Husserl (1859-1938), filósofo alemão, postulou uma terceira via, uma possibilidade que nos colocaria no mesmo plano da realidade, antes de todo raciocínio (DARTIGUES, 1973, p.78), preocupando-se em conhecer as coisas a partir delas mesmas, sem preconceitos ou argumentações (CARVALHO, 1997). A esse respeito, LYOTARD (1954, p. 09) comenta: "0 célebre "por entre parênteses" consiste em primeiro lugar, em dispensar uma cultura, uma história, em refazer todo 0 saber elevando-se a um não saber radical".

Husserl propôs o entendimento dos fenômenos. Tal 
entendimento teria como meta o conhecimento da vivência de determinada realidade por meio da descrição dos fenômenos, feita de forma mais completa e fiel possivel, isenta do juizo dos fatos (RIBEIRO, 2003). Uma vez conseguida a descrição do fenômeno, chega-se à sua essência. A essência é o objeto da pesquisa fenomenológica. Segundo RIBEIRO (2003), a essência é o conceito universal ou forma capaz de se verificar invariavelmente em diferentes indivíduos, aquilo que permanece idêntico através das variações (LYOTARD, 1954, p.20).

0 método fenomenológico parte da intuição ou da consciência dos objetos. A redução é o recurso da fenomenologia para se chegar ao fenômeno como tal, ou à essência. A redução fenomenológica consiste em retornar à experiência vivida e sobre ela fazer uma profunda reflexão que permita chegar à essência do conhecimento. Esse conhecimento tem como objetivo a apreensão do sentido ou do significado da vivência subjetiva (FORGUIERI, 1993). Sobre a vivência subjetiva, LYOTARD (1954, p. 21) aponta: "Todo objeto é objeto para uma consciência (...) importa descrever neste momento o modo como eu conheço o objeto e como o objeto é para mim".

A fenomenologia foi, assim, sistematizada no início do século XX (1901) com o primeiro trabalho sobre o assunto. A partir de então, outras áreas do conhecimento passaram a se valer da fenomenologia. Na área da psiquiatria, a investigação fenomenológica surgiu na Europa, com Karl Jaspers (1913), que, com a publicação de sua obra Psicopatologia Geral, marcou o surgimento da psiquiatria fenomenológica. $\mathrm{Na}$ área da psicologia, os primeiros trabalhos surgiram nos Estados Unidos na década de 1970 (FORGHIERI, 1993, p.10). Em outros domínios também houve a influência fenomenológica, notadamente nas áreas da vida afetiva e religião (SCHELER), artes (GEIGER e INGARDEN), direito, sociologia, etc (DARTIGUES, 1993, p.80). Em 1928, Roman Ingarden, ${ }^{1}$ após publicar A Obra de Arte Literária, expandiu sua discussão também para a música.

A fenomenologia, no contexto do presente trabalho, é algo que potencialmente permite nos aproximar da prática interpretativa, capturando aquilo que essencialmente conduz as escolhas do intérprete ao longo da performance musical. A esse respeito, CLIFTON (1983) busca aplicar o método fenomenológico à vivência musical. Para tanto, estabeleceu essências que constituem o fenômeno musical: tempo, espaço, elemento lúdico e sentimento.

A percepção temporal (o tempo) na música diz respeito à vivência subjetiva de um tempo que não é 0 cronológico, e, sim, o das lembranças evocadas a partir de mecanismos de reconhecimento de estruturas musicais. Tal reconhecimento pode ser imediato (retenção) ou uma expectativa daquilo que reconduz a algo conhecido há pouco (protensão) ou mais remotamente (reprodução).

O espaço, segundo CLIFTON, emana da percepção das texturas. Esse, portanto, não é geométrico ou palpável. É o resultado da percepção simultânea da percepção das alturas, timbre e textura, que registra profundidade. A estruturação composicional determina o espaço fenomenológico na música, descrito como relevos.

0 elemento lúdico nos remete à idéia de jogo. É o jogo que ocorre na construção composicional, no processo de reconhecimento de formas, na preparação, na performance e na apreciação musical. É como um quebra-cabeça, que se revela conforme as peças vão se encaixando. Vivenciar cada "encaixe" faz parte da experiência do elemento lúdico na música.

0 sentimento é como uma decorrência das outras essências, na medida em que se traduz no sentimento de posse, a sensação recíproca e irreversivel de fazer parte um do outro: Música $\leftarrow \rightarrow$ Sujeito.

A questão é se verificar objetivamente o ponto de contato entre as essências fenomenológicas, a estruturação harmônica e as associações com os significados do texto da peça.

\section{3- Procedimentos Metodológicos \\ Serão quatro etapas descritas a seguir: \\ - $\quad$ Tradução do texto da peça. \\ - $\quad$ Análise harmônica funcional. \\ - Análise fenomenológica. \\ - Construção Interpretativa.}

\section{4- Tradução do Texto da peça}

"Bajulans sibi crucem Jesus exivit eum qui dicitur Calvarie locum".

"Carregando sua cruz, Jesus foi para o lugar chamado Calvário". (NEVES, p. 86).

\section{5- Análise Harmônica Funcional}

A análise apresentada a seguir (vide figura 1, p. 92) é apenas uma descrição das funções harmônicas, muito embora a mesma já possa revelar aspectos da estruturação premeditadamente incluídos em função do texto. Essa suposição ganha força diante de ocorrências muito consistentes para terem acontecido simplesmente ao acaso. Esse é o caso, por exemplo, nos seguintes trechos: Compassos 9 e 10: Primeira ocorrência da palavra cruz, que parece se traduzir do ponto de vista harmônico nas funções tônicas que nesse momento estão enfatizadas.

Compasso 11: A palavra Jesus coincide com a ocorrência de sofisticações que até então não haviam se apresentado - Acorde de subdominante da subdominante na primeira inversão (único de toda a peça); e bordadura na $3^{\text {a }}$ voz.

Três pausas parecem indicar momentos da paixão, como que quedas e/ou mesmo perplexidade pela constatação de presenciar o próprio Cristo consumido pelo sofrimento.

A peça tem 33 compassos com uma bordadura fazendo a transição para os dois compassos finais, que parecem apenas consumar a morte do crucificado. 
Bajulans

Manoel Dias de Oliveira

CSimonneFonseca

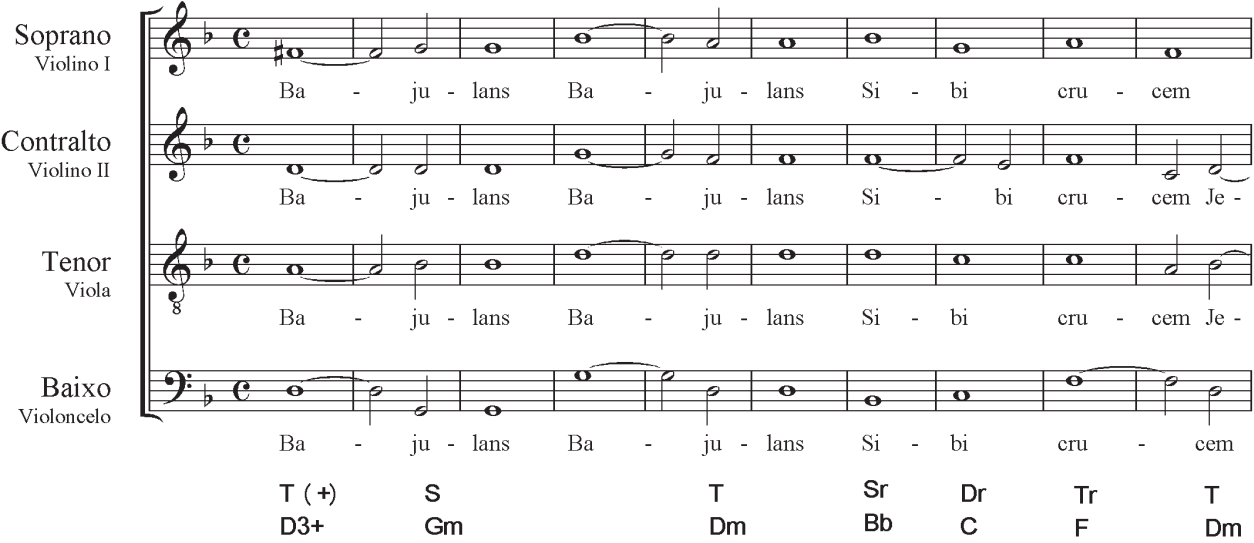
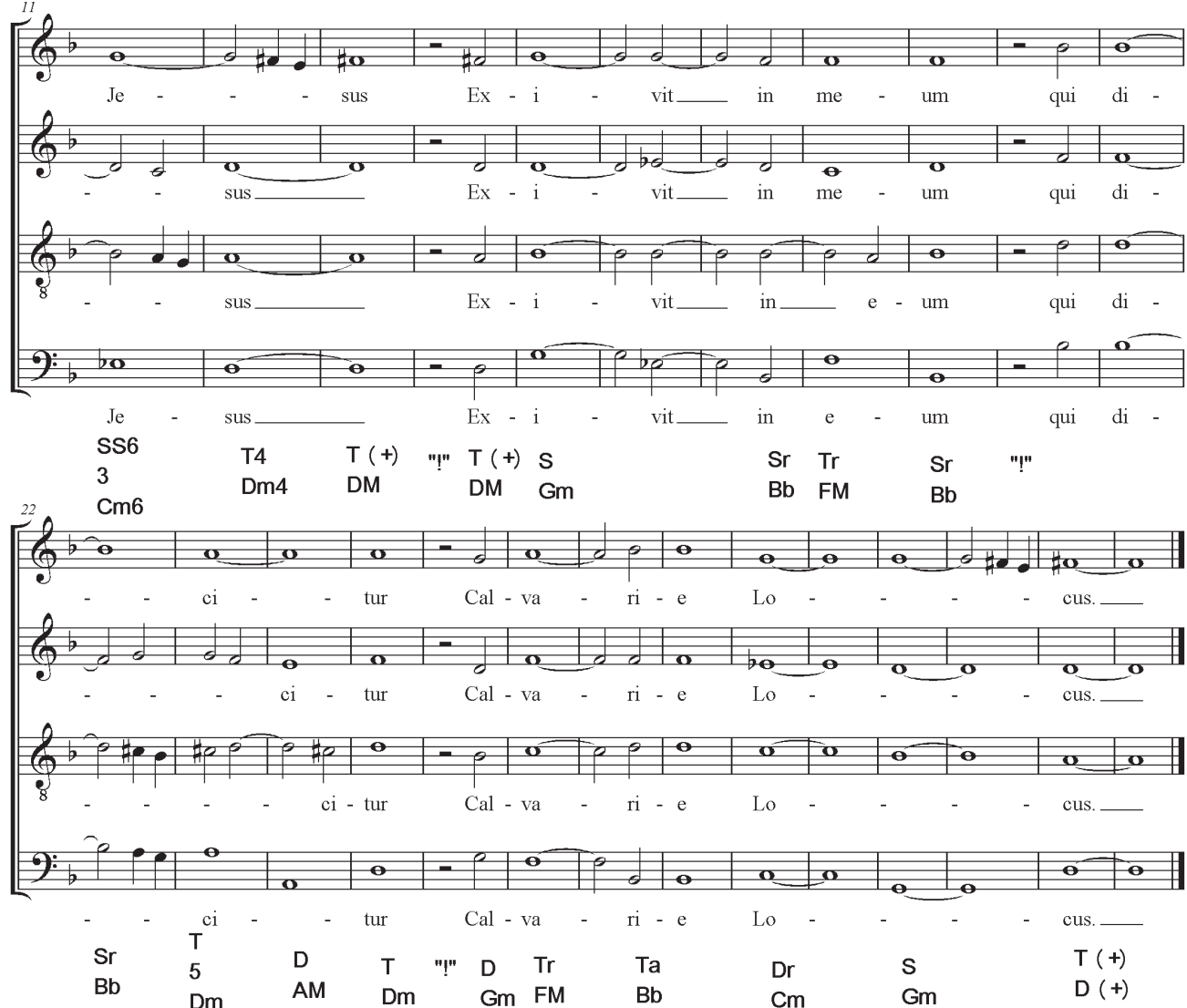

Fig.1 - Grade de Bajulans - Manoel Dias de Oliveira: Abaixo da letra do canto são sinalizadas as funções harmônicas e a nomenclatura de cada acorde segundo KOELLREUTTER (1986), como se segue: T=Tônica; S=Subdominante;

$\mathrm{D}=$ Dominante; $r=$ relativa; $\mathrm{a}=$ antirrelativa; $\mathrm{SS}=$ Subdominante da subdominante; $\mathrm{D} 3+=$ Ré Maior na 1a inversão; $\mathrm{Gm}=\mathrm{Sol}$ menor; $\mathrm{Dm}=$ Ré menor; $\mathrm{Bb}=\mathrm{Si}$ bemol; $\mathrm{C}=\mathrm{Dó} ; \mathrm{FM}=\mathrm{Fá}$ Maior; $\mathrm{Cm6=Dó} \mathrm{menor} \mathrm{com} \mathrm{6a;} \mathrm{DM}=$ Ré Maior; $\mathrm{AM}=$ Lá Maior;

$\mathrm{Cm}=$ Dó menor.

\section{6- Análise Fenomenológica}

Serão tratados aspectos distintos das essências, quais sejam, tempo, espaço, elemento lúdico e sentimento:

6.1- Tempo: Segundo CLIFTON (1983), o tempo não é algo que estabelece sentido por si só, mas necessariamente é construído pelas experiências dos sujeitos. Apresentar a peça tocada por instrumentos de sopro / metais (trombones) requer não só uma disciplina técnica no que diz respeito à manutenção do fluxo de ar diante de um fraseado que 
pouco varia; é algo que invade o intérprete, traduzindo-se pela sensação de peso, sacrifício e perseverança, aspectos da vivência do Calvário. Quando se observa o desenho rítmico que segue a palavra "bajulans" - que significa segurando - tem-se que a repetição é premeditadamente empregada como uma opção de ênfase. Ao mesmo tempo, essa ênfase é logo percebida pelo intérprete, que se dá conta da célula rítmica que ora se repete. Tal mecanismo, na fenomenologia da música, é chamado de "protensão". Esse tempo, que parece transcorrer de forma lenta, ganha novo colorido com variações na superfície espacial da música (como indicado no próximo item) no compasso 11, com a incidência de uma construção harmônica até então não empregada e a ocorrência de uma bordadura (observe na figura da p. 92). A importância disso está no fato de exatamente nesse local estar indicada a palavra "JESUS", como que numa cena onde os expectadores assistem a passagem do crucificado em franca paixão. Após esse evento, a peça retoma seu tempo fenomenológico, o lento que é traduzido por uma árida peregrinação pelo Calvário.

6.2- Espaço: Ao longo de toda a peça, observa-se uma superfície lisa, na medida em que não se ressaltam grandes variações no desenho das durações. São acordes que vão se encadeando. Há apenas uma variação dessa superfície justamente no momento em que se observa a palavra "Jesus" - compasso 11 - onde se encontram bordaduras (veja na página anterior). As três pausas suscitam a existência de uma superfície de baixo relevo - com interrupção do fluxo sonoro.

6.3- Elemento Lúdico: 0 "jogo" deliberado na construção composicional é realçado, principalmente, nas escolhas harmônicas, e, mais uma vez, esse é mais evidente no compasso 11, onde se observa uma sofisticação até então não utilizada. A escolha de uma subdominante da subdominante na primeira inversão traz toda uma sensação de suspensão à percepção auditiva. Especular acerca da intenção do compositor é puro exercício de extrapolação, todavia, parece exercer um papel importante na elaboração dos nexos interpretativos. Imaginar a cena de Jesus surgindo na via crucis realmente traz, até para a mais das isentas impressões, uma sensação de suspensão, sobretudo por que essa leitura se dá através do estímulo auditivo do acorde acima referido.

6.4- Sentimento: 0 sentimento é, no caso dessa peça, a vivência elaborada na trama da via crucis, sustentada pelo texto do canto, pela harmonia, e pelo tempo fenomenológico. Tais materiais contribuem para uma maior densidade da experiência musical e para um gradativo processo de construção da intimidade na construção interpretativa.

\section{7- Construção Interpretativa}

0 grande desafio é traduzir em sons aquilo que no canto já possui um significado por si mesmo, que é a palavra. Num quarteto de trombones não há como fazer isso de forma integral, muito embora se possam gerar informações musicais a partir das ênfases que se colocam nas frases, nas nuances da agógica e no conjunto das quatro vozes. 0 colorido do timbre pode enfatizar o caráter da peça. Por exemplo, no caso da tonalidade menor, que já carrega um colorido mais denso, pode-se enriquecer a interpretação combinando-se timbres mais escuros nos trombones. 0 compartilhamento da respiração é algo que traz a idéia de conjunto, de unidade, que se pode entender como a caminhada do próprio crucificado. Nessa, a pulsação lenta deve também ser algo que traduza a idéia de sofrimento. Outra questão importante é poder entender o que venha a ser a via crucis e como se dá essa cena na cultura popular. A atmosfera barroca das cidades históricas e o enorme espaço que é dado a esse tipo de tradição colocam o barroco mineiro como ponto de referência interpretativa para peças desse periodo.

\section{8- Resultados}

Os resultados obtidos de um processo de análise fenomenológica são, via de regra, um aprofundamento do entendimento acerca da peça. No caso da peça Bajulans, a questão se torna interessante pela aparente simplicidade de sua estrutura, quando observada à primeira vista. Retirar tal peça do estatuto da facilidade e criar sobre essa suposta simplicidade algo que possa levar impacto aos ouvintes é tarefa para os intérpretes. Ao detectar relações entre a harmonia, o significado do texto, o tempo e o espaço, estão se configurando parâmetros norteadores para uma construção interpretativa. Esse foi o caso, por exemplo, no compasso 11. Em todos os momentos em que se apresentam informações que estabelecem mais sentido para os intérpretes, ocorre uma escuta mais elaborada em termos do reconhecimento das diferentes vozes pelos diferentes intérpretes.

\section{9- Discussão}

A integração entre elementos harmônicos e o referencial fenomenológico, no contexto desse trabalho, foi apenas uma escolha metodológica. A idéia de se ter várias fontes de informação, como que construindo uma rede associativa, permeia essa escolha. A evidência encontrada através de um método pode ser reforçada ou mesmo facilitada por outro. 0 resultado desse compartilhamento pode ter repercussões importantes nas opções interpretativas musicais.

\section{0- Considerações Finais}

A construção interpretativa deveria ser o resultado de inúmeras associações advindas da descoberta de esquemas estruturais, os quais, via de regra, são deliberadamente elaborados pelo compositor. Trazer essa forma de lidar com a prática interpretativa é apostar num processo mais elaborado e sofisticado que nem sempre é observado no âmbito da performance musical. A análise musical fenomenológica fomenta curiosidades acerca de parâmetros não muito tradicionais na performance 
musical, muito embora, tais significados possam emergir de outros referenciais. As essências fenomenológicas descritas por CLIFTON (1983) podem fornecer material suficientemente relevante para uma performance mais consistente. Nessa, o intérprete torna-se sujeito da música simultaneamente quando a mesma se apropria do intérprete, formando assim, uma espécie de integração participativa da qual os elementos estruturadores da música são apreendidos de forma gradativamente mais aprofundada ao longo de um processo artesanal. Tal abordagem abre uma discussão relativa ao tempo como elemento importante no processo interpretativo. Não se pode amadurecer artificialmente uma interpretação, muito embora, novos elementos acerca da percepção do intérprete possam fornecer subsidios suficientes para se otimizar tal processo.

\section{Referências}

CARVALHO, 0. Seminário de Filosofia. Disponivel em: http://www.olavodecarvalho.org/apostilas/serconhecer.htm Acesso em 11/09/2007.

CLIFTON, Thomas. Music as heard: a study in applied phenomenology. New Haven: Yale University Press, 1983. 298p. DARTIGUES, A. 0 que é a fenomenologia? Trad. Ma José J. G. de Almeida. Rio de Janeiro: Eldorado, 1973. 163 p Tradução de: Qu'est-ce que la phénoménologie?).

FORGHIERI, Y.C. Psicologia Fenomenológica: Fundamentos, Método e Pesquisas. 1 ed. São Paulo: Pioneira, 1993. 81 p. LYOTARD, J.F. A Fenomenologia. Trad. Armindo Rodrigues. Lisboa: Edições 70, 1954. 119 p. (Tradução de: La phénoménologie).

NEVES, J. M. Música Sacra Mineira: catálogo de obras. 1 ed. Rio de Janeiro: Imprinta, 1997. 137 p.

RIBEIRO JR, J. Introdução à Fenomenologia. 1 ed. Campinas: Edicamp, 2003. 84 p.

\section{Leitura Recomendada}

CASTRO, Antônio José Jardim e. Música: Vigência do Pensar Poético. 1997. 303 f. Tese (Doutorado em Ciência da Literatura-Poética) Faculdade de Letras, Universidade federal do Rio de Janeiro, Rio de Janeiro, 1997.

CAVAZOTTI, André. Refletindo sobre o conhecimento do fenômeno musical: um estudo multi-caso sobre recepções do segundo movimento de (Três Miniaturas) para Violino e Piano de K. Penderecki. 2003. 13 p. Manuscrito não publicado. CHAUI, M.S. (Ed.). Textos Selecionados: Maurice Merleau-Ponty. Trad. Marilena de Souza Chauí. 2. ed. São Paulo: Abril Cultural, 1980. 260 p.

HUSSERL, E. Investigações lógicas. Tradução de Zeljko Loparic e Andréia Maria Altino de Campos Loparic. São Paulo: Nova Cultural, 1996. 224 p. Título original: Logishe untersuchungen.

KOELLREUTTER, H. J. Harmonia Funcional: Introdução à teoria das funções harmônicas. 3 ed. São Paulo: Ricordi, 1986. 72 p. MACIEL, S.M. Corpo Invisivel: uma nova leitura na filosofia de Merleau-Ponty. 1 ed. Porto Alegre: EDIPUCRS, 1997. 164 p. OCHSNER, K. Are affective events richly recollected or simply familiar? The experience and process of recognizing feelings past. Journal of Experimental Psychology: General, Cambridge, MA, v. 129, n. 2, p. 242-61, jun. 2000.

POMBO, F. A arte e sua filiação fenomenológica. Disponivel em: http://www.ciberkiosk.pt/arquivo/ciberkiosk3/arte/jan.htm. Acesso em 11/09/2004.

THOMASSON, A. The Musical work. In STANFORD ENCYCLOPEDIA OF PHILOSOPHY. Disponivel em: http://plato.stanford. edu/entries/ingarden/. Acesso em 10/09/2007.

Sérgio de Figueiredo Rocha possui Graduação em Educação Física (1988), Medicina (1995) e Música (2002), todas concluídas na UFMG; Residência Médica em Psiquiatria pelo Hospital das Clínicas da UFMG (1999), Especialização em Música Brasileira pela UEMG (2001) e Mestrado em Música pela UFMG (2005). Atualmente é Professor Assistente na Universidade Federal de São João Del Rei (UFSJ). Nessa instituição tem se inserido em atividades de extensão como o Coral de Trombones e participou da organização de eventos como os "Vertentes Musicais I e II", atividade cuja principal proposta foi pensar a prática musical a partir de vários olhares do saber. Em 2005 publicou o livro: "Memória: uma chave afetiva para a música", cuja essência e interesse é a inter-relação entre neurociências, psicologia e música. Desde a criação do curso de música na Universidade Federal de São João del Rei, participa do Grupo de Pesquisa organizado pelo Departamento de Música daquela instituição chamado "Vertentes Musicais", o qual é cadastrado no CNPq.

\section{Nota}

' Filósofo polonês (1893-1970), aluno de Husserl. 